ECOLOGICA, Vol. 28, No 103 (2021), 459-465

https://doi.org/10.18485/ecologica.2021.28.103.17

Originalni naučni rad

UDC: 796.035:616-036.21

\title{
Uloga faktora okruženja u wellness-u pre i tokom pandemije COVID-19
}

\section{Role of environmental factors in wellness after pandemic COVID-19}

\author{
Jovanka Popović ${ }^{1}$, Milošević Dragan ${ }^{2 *}$, Avakumović Jelena ${ }^{3}$ \\ 1,2,3Fakultet za menadžment, Njegoševa 1a, 21205 Sremski Karlovci, Univerzitet Union - Nikola Tesla, \\ Beograd, Srbija / \\ Faculty of Management, Njegoševa 1a, 21205 Sremski Karlovci, University Union - Nikola Tesla, \\ Belgrade, Serbia \\ *Autor za prepisku / Corresponding author
}

Rad primljen / Received: 14.12.2020, Rad prihvaćen / Accepted: 06.08.2021.

Sažetak: Wellnes možemo definisati kao bavljenje aktivnostima,u cilju izbora načina života koji dovodi do opšteg zdravlja. Opšte zdravlje ima šest dimenzija: fizičko, mentalno, socijalno, emocionalno, duhovno zdravlje i prirodno okruženje. Ostvaruje se kontinuiranim naporima da se razvijaju i održavaju sve dimenzije opšteg zdravlja. Cilj rada je da se istraže uloge ekoloških faktora u wellnes-u posle pandemije COVID-19. Kroz analizu literature dobijeni su rezultati istraživanja. Čak $80 \%$ uzroka naših hroničnih bolesti dolazi iz naše okoline. Okruženje koje utiče na naše zdravlje sastoji se od prirodnog, zdravstvenog sistema i socio-ekonomskog sistema koji preedstavljajju način života koji vodimo. Preostalih $20 \%$ faktora zavise od genetskih faktora. Oni takođe mogu biti inicirani negativnim uticajem faktora okoline i dovesti do pojave hroničnih bolesti. Donošenjem zdravih odluka možemo u velikoj meri da utičemo na smanjenje hroničnih i mentalnih bolesti. Mere za suzbijanje pandemije COVID-19 uticale su na to da se naš životni prostor bio sveden na nivo stambenog prostora. Wellness treba da pronađe odgovore i sačuva naše zdravlje radi pripreme za obnovu života po završetku pandemije.

Ključne reči: wellness, opšte zdravlje, Covid 19 pandemija, faktori okruženja, životni stil.

\begin{abstract}
Wellness can be defined as engaging in activities, choices and lifestyles that lead to general health. General health has its six dimensions: physical, mental, social, emotional, spiritual health and natural environment. Continuous efforts are made to develop and maintain all dimensions of general health. The work aims to explore the role of environmental factors in wellness following the Covid 19 pandemic. Through the analysis of literature, the results of the research were obtained. As many as $80 \%$ of the causes of our chronic diseases come from our environment. The environment that affects our health consists of a natural, health system and socio-economic system through the way we lead. The remaining $20 \%$ of factors depend on genetic factors. They can also be initiated by the impact of environmental factors and lead to the emergence of chronic diseases that our ancestors did not have. By making healthy decisions, we can greatly influence the reduction of chronic and mental illnesses. Measures to contain the Covid 19 pandemic have affected our living space to the level of housing. Wellness needs to find answers and preserve our health in preparation for the restoration of life after the end of the pandemic.
\end{abstract}

Keywords: wellness, general health, Covid 19 pandemics, environmental factors, lifestyle.

\footnotetext{
${ }^{1}$ orcid.org/0000-0003-0263-0295, e-mail: jovanka.popovic@famns.edu.rs

2orcid.org/0000-0002-5979-2562, e-mail: dragan.milosevic@famns.edu.rs

${ }^{3}$ orcid.org/0000-0002-7856-8064, e-mail: jelena.avakumovic@famns.edu.rs
} 


\section{UVOD / INTRODUCTION}

Svetska zdravstvena organizacija na svom sajtu (World Health Organisation - WHO, 2020) navodi da se pre pandemije Covid-19 do 2019. g., mogu definisati 10 glavnih uzroka smrti usled ne zaraznih bolesti. Sve ne zarazne bolesti su tokom 2019 g. činile 74\% smrtnih slučajeva u svetu. Tako da su zarazne bolesti bile uzrok smrti jedne četvrtine populacije u svetu, uglavnom u siromašnim zemljama.

lako nemaju smrtne ishode, ovim ciframa svakako treba dodati konstantan rast mentalnih bolesti pre pojave pandemije Corona 19 virusa. Tako je $2017 \mathrm{~g}$. oko $15 \%$ svetske populacije zabeležio neki vid mentalnih bolesti u skalama od lakših do težih. Depresija je porasla za više od $18 \%$ u odnosu na period 2005 do 2015 g. prema (Global Wellness Institute GWI, 2020b). Usamljenost i osećaj socijalnog otuđenja smanjuju našu mogućnost empatije da pružimo drugome pomoć.

Svetska populacija u proseku ima povećanu telesnu težinu u odnosu na 1975 . g. za $39 \%$. Povećanje telesne težine usled gojaznosti i nedovoljne fizičke aktivnosti je uzrok velikog broja hroničnih bolesti kao što su dijabetes, kardio vaskularne bolesti do anksioznosti i depresije. Pogrešan način života sa pogrešnim izborima vodi do razvoja hroničnih bolesti koja sa svoje strane povećavaju rizik smanjenja životnog veka i prerane smrti. Kao rezultat navedenog je i osećaj usamljenosti i socijalne otuđenosti koji su pogodili 9\% Japanaca, 22\% Amerikanaca i i 23\% Britanaca, na osnovu istraživanja Global Wellness Instituta (Global Wellness Institute - GWI, 2020b) .

Patnja koju je izazvala pandemija odnosi se ne samo na samu bolest već i na razne društvene posledice kao što su stresovi izazvani strahom od gubitka posla, nedostatka sredstava za životne potrebe, socijalne izolovanosti, osećaja besa i nemoći i mentalnih bolesti. Opšte zdravstveno stanje nikad nije bilo bitnije nego u ovakvim situacijama jer je jedino ono nudilo mogućnost oporavka i vraćanja na stari način života pre pandemije (Yeung \& Johnston, 2020). Medicinski pojam održavanja zdravlja je u suštini reaktivan (slika 1), jer reaguje na već nastale poremećaje u zdravstvenom stanju čoveka.

\begin{tabular}{|c|c|}
\hline Poor Health & $\begin{array}{l}\text { Optimal S } \\
\text { Of Well-be }\end{array}$ \\
\hline Medical Paradigm & Wellness Paradigm \\
\hline Feel Better & Thrive \\
\hline Treat \& cure illness & Maintain \& improve health \\
\hline Corrective & Preventive \\
\hline Episodic & Holistic \\
\hline Clinical-responsibility & Individual responsibility \\
\hline Compartmentalized & Integrated into life \\
\hline
\end{tabular}

Source: Global Wellness Institute

Slika 1 - Kontinum zdravlja / Figure 1 - Health Continuum Izvor / Source: (Global Wellness Institute - GWI, 2021)

Wellness je proaktivan pristup koji je fokusiran na aktivnosti u cilju prevencije i maksimizacije vitalnosti. Sprovodi se kroz usvajanje stavova i načina života koje sprečavaju nastajanje neravnoteže u opštem zdravlju i vode poboljšanju kvaliteta života. U ovom pristupu su osim fizičkog zdravlja prisutne i druge dimenzije (kao što je mentalno zdravlje na primer) koje se uzimaju u obzir.
U svojoj knjizi Rene Dubos je 1968. prvi upotrebio širi termin "wellness" kako se danas koristi u literaturi (Dubos \& Mechanic, 1968). Za svoj rad i nove poglede ovaj mikro-biologi i patolog dobio je prestižnu Pultzer-ovu nagradu 1969. g. Njegova istraživanja su se zasnivala na tezi da tehnologija dehumanizuje ljude i da zato nauku treba humanizovati.

Postoji više definicija wellness-a, prema tome šta sve obuhvata ovaj pojam. Prema dr Bigl Hettler-u 
suosnivač (National Wellness Institute - NWI, 2021) na svom sajtu daje definiciju wellness-a koja navodi da je „wellness je aktivan proces kroz koji ljudi postaju svesni i donose odluke o uspešnom postojanju“. Prema drugom izvoru (Bradley, 2020) navodi se da je wellness krajnje jednostavno definisan kao proces aktivnog traženja sveukupnog dobrog zdravlja kroz dobar i zdrav način života. Sličnu definiciju wellnessa navodi (Global Wellness Institute - GWI, 2021) kao „aktivno bavljenje aktivnostima, izborima i načinom života koji vode u stanje holističkog (sveukupnog) zdravlja“.

Cilj ovog istraživanja su uloge koje imaju faktori okruženja u wellness-u, tokom i nakon pandemije Covid-19.

\section{MATERIJALI I METODE / MATERIALS AND METHODS}

Ovo istraživanje je koristilo izvore podataka sa interneta. Analizom sadržaja i deskriptivnom statistikom sprovedena je obrada podataka i izvođenje zaključaka.

\section{REZULTATI I DISKUSIJA /} RESULTS AND DISCUSSION

Model holističkog zdravlja u wellness-u

Prema dr Bigl Hettler-u (National Wellness Institute - NWI, 2021) model wellness-a ima šest dimenzija zdravlja. To su: emocionalna, profesionalna, fizička, socijalna, intelektualna i duhovna dimenzija. Težnjom ka ispunjavanju svih dimenzija teži se sveobuhvatnom ili holističkom osećaju zdravlja, dobrobiti i ispunjenosti.

Nešto drugačiji pristup, prikazan na slici 2, navodi eminentni (Global Wellness Institute - GWI, 2020b, str. 4). Ovaj izvor navodi da se wellness sastoji od sledećih elemenata ili kako su definisali dimenzija zdravlja:

1. Fizičko zdravlje, koje se zasniva na zdravom telu koje je rezultat vežbanja, pravilne i uravnotežene ishrane, sna itd.

2. Mentalno zdravlje, koje se zasniva na razvoju intelekta kroz stalno učenje, rešavanje problema, kreativnost itd.

3. Duhovno zdravlje, kroz potragu pojedinca za smislom i svrhom ljudskog postojanja.

4. Emocionalno zdravlje, kroz ostvarivanje kontakata sa drugim ljudima, biti svestan i iskazati svoja osećanja, razumeti i prihvatiti osećanja drugih ljudi.

5. Društveno zdravlje. Povezivanje sa drugim ljudima. Integracija u socijalne zajednice, doprinos zajednici kroz interakciju sa članovima.
6. Životna sredina. Čine je zdravo fizičko okruženje, zelene površine u gradovima, kao i hrana voda, vazduh i sl..

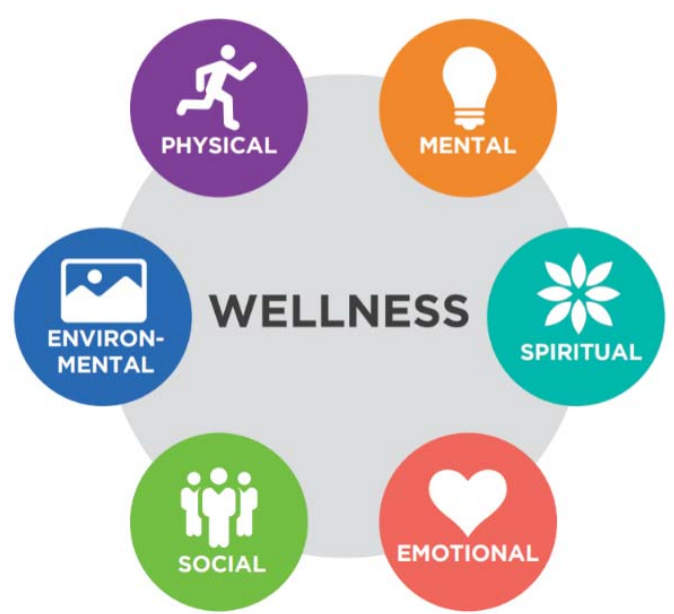

Slika 2 - Šestodimenzioni model opšteg zdravlja Figure 2 - Six-dimensionalvmodel og general health Izvor / Source: (Global Wellness Institute - GWI, 2020b)

Za svaki od navedenih modela je karakteristično da ima sličan pristup koji je višedimenzionalan i holistički. Sve dimenzije su međusobno povezane. Svaka od dimenzija na svoj način, doprinosi poboljšanju opšteg stanja zdravlja. Razvoj se ne može sprovesti razvojem samo jednog dela dimenzija, već moraju biti ispunjene sve dimenzije zdravlja. To je jedan kontinualan, dinamičan proces, koji se sprovodi kroz ceo životni vek čoveka. Tokom rada na svojem napredovanju, čovek postaje svestan svojih potreba, trenutnog stanja kao i mogućnosti za dalje napredovanje. Da bi se ostvario optimalan wellness potrebno je da svaki pojedinac ostvari svoj potencijal u svim dimenzijama.

Samo opšte zdravlje se može definisati kroz različita stanja od smrti, invaliditeta do optimalnog stanja zdravlja. Ovo stanje se postiže kada se ostvari pun potencijal pojedinca u svim dimenzijama zdravlja. Sveukupno dobro zdravlje se postiže velikim delom donošenjem dobrih životnih odluka, kroz dobar, zdrav i uravnotežen način života. Proces koji ima svoje periode napredovanja ali i periode nazadovanja. Tako da kad se jednom postigne optimalno stanje, mora se dalje raditi na njegovom održavanju, tokom celog životnog veka čoveka.

Uloga spoljašnjih i ekoloških faktora okruženja u našem wellness ekosistemu

Mnogi faktori iz životnog okruženja utiču na naše mogućnosti da ostanemo zdravi. Sprovedeno istraživanje (Rappaport \& Smith, 2010) ukazuje da se 80 do $90 \%$ našeg zdravlja nalazi pod uticajem faktora 
okruženja. Bolesti uzrokovane efektima iz okruženja, prema (Rappaport \& Smith, 2010) u 23\% dovode do smrtnog ishoda kod odraslih. Kad su deca u pitanju to je $26 \%$. Populacija dece, starih, sa hroničnim obolenjima kao i siromašni predstavljaju grupe ljudi koji su posebno osetljivi na rizike iz okruženja. Spoljašnji i faktori okruženja prema (Global Wellness Institute - GWI, 2020b, str. 16) odnose se na: zdravstveni sistem, socijalno okruženje koje imamo, masovni saobraćaj koji koristimo, obrazovanje, kulturu kojoj pripadamo, prijatelje sa kojima pravimo i održavamo kontakte, sredinu u kojoj živimo i provodimo vreme. Navedeni izvor zaključuje da ne možemo ostati niti postati zdravi u celosti ukoliko ne kreiramo naše okruženje koje će podržati naše napore a ne ograničavati in.

Ostatak od 10 do $20 \%$ uticaja koji definišu naše opšte zdravlje odnosi se na genetski materijal koji smo nasledili od svojih predaka. Genetske predispozicije su potencijalne pretnje po zdravlje, koje se mogu inicirati raznim negativnim faktorima iz okruženja.

\section{HEALTH OUTCOMES}

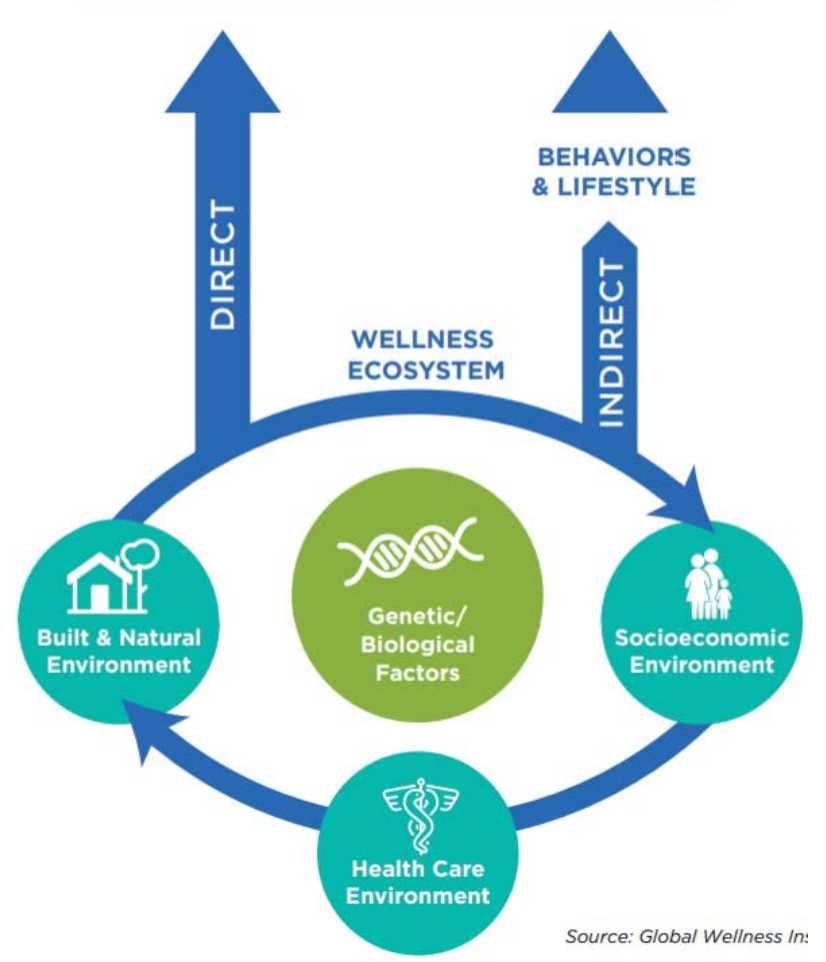

Slika 3 - Do 80-90\% naših zdravstvenih ishoda zavisi od spoljašnjih i ekoloških faktora u našem wellness ekosistemu

Figure 3 - Up to 80-90\% of our health outcomes depend on external and environmental factors in our wellness ecosystem

Izvor / Source: (Global Wellness Institute - GWI, 2020b)
Uticaji iz okruženja (slika 3) se mogu podeliti u tri kategorije (Global Wellness Institute - GWI, 2020b, str. 16):

- $\quad$ Prirodno okruženje. Tu su naravno i procene rizika oboljevanja usled zagađenja, buke klimatskih promena itd. (Prüss-Ustün, Wolf, Corvalán, Bos, \& Neira, 2016)

- Zdravstveno okruženje ali i ostali komunalni sistemi, kao što je vodosnabdevanje, dostava hrane, javni prevoz i ostale usluge.

- Socio-ekonomski sistem kao okruženje. Predstavlja sistem naših odnosa koji kreiramo kroz odnos sa drugim ljudima i poslom kojim se bavimo.

Uticaju mogu biti direktni i indirektni. Direktni se vezuju za samo prirodno okruženje (zelene i stambene površine, vazduh, voda, hrana), dok se indirektni odnose na naš stil života i odnose koje gradimo sa drugim ljudima.

Zagađenja vazduha, zemlje i hrane predstavljaju velike rizike po zdravlje. Zagađenje vazduha u kući je nekoliko puta opasnije nego spoljašnje zagađenje. $U$ zemljama sa niskim prihodima gde se za kuvanje i grejanje koriste ugalj, kerozin i biomasa zagađenje vazduha u kući može biti 2 do 5 puta veće nego spoljašnje. Prema podacima iz 2016. g. (World Healt Organisation - WHO, Climate \& Clean Air CoalitionCCAC, 2021) i (World Health Organization - WHO, 2018), 4,3 miliona smrtnih slučajeva prouzrokovano je unutrašnjim zagađenjem vazduha (misli sa na zatvorene prostore u kojima živimo) dok je još 3 miliona rezultat spoljnjeg zagađenja vazduha. Smatra se da je zagađenje vazduha uzročnik trećine smrtnih slučajeva usled mnogih oboljenja kao što su moždani udar, infarkt, kancer pluća, i hronične respiratorne bolesti. Više od $80 \%$ svetske populacije živi u gradovima. Pri tome većina gradova ima nivo zagađenja vazduha, a često i vode koje prevazilaze dozvoljene granice. Od tog broja $98 \%$ gradova se nalazi u zemljama gde stanovništvo ima nizak dohodak.

Uloga koncepta pametnih gradova je višestruka. Jedan od ključnih koncepata je razvoj ljudske civilizacije putem implementacije inovativnih tehnologija u eri četvrte industrijske revolucije (Munitlak Ivanović, 2020). Urbane sredine ulažu sve veća sredstva za rešavanje svojih ekoloških problema (Beke-Trivunac \& Jovanović, 2020). Modernizacija gradske infrastrukture (kanalizacija, vodosnabdevanje, prečiščavanje otpadnih voda, izgradnja sanitarnih deponija) doprinosi sprečavanju razvoja infekcionih bolesti.

\section{Ekološki efekti pandemije COVID-19}

Pandemija uzrokovana virusom COVID-19 je ostavila traga na skoro sve aspekte ljudskog života kako zajednice u celini tako i pojedinaca. Uticaji pandemije na ljudsku civilizaciju imaju širok spektar 
od drastičnog pada ekonomskih aktivnosti do efekata po prirodnu sredinu (Lukinović \& Jovanović, 2020).

Mere politika vlada da zaustave pandemiju COVID-19 ostavile su brojne efekte na spoljne i ekološke faktore wellnesa. Možemo in posmatrati globalno ali i na nivou pojedinaca.

Globalno gledano, ekološki efekti pandemije COVID-19 (slika 4) prema (Rume \& Didar-UI Islam, 2020) mogu se podeliti na pozitivne i negativne. Kao najznačajniji pozitivni efekti navedeni su rezultati mera ograničenog kretanja što je dovelo do usporavanja ekonomskih aktivnosti i putovanja. Ovo je izazvalo čitav niz pozitivnih efekata kao što su smanjenje potrošnje fosilnih goriva, upotrebe resursa $i$ odlaganja industrijskog otpada, smanjenje transportnih i industrijskih aktivnosti, pritiska na turističke destinacije. Došlo i do smanjenja zagađenja vazduha (za 30 do 60\%) i vode, buke, emisije štetnih gasova i pritiska na turističke destinacije u odnosu na isti period prethodne godine. Ovo se najviše odrazilo na velike prenaseljene gradove. Ovo je omogućilo ob- navljanje ekoloških sistema. Kao negativni efekti se prema istom izvoru mogu navesti pojava velike količine otpada od sredstava za ličnu zaštitu (eng. personal protection eqipment-PPE), pritisak na sistem zdravstva, odlaganje medicinskog otpada. Posledica su rast količina opasnog i medicinskog otpada, rast količine komunalnog otpada, smanjenje aktivnosti recikliranja.

Ako efekte posmatramo iz ugla pojedinaca i porodica, dobijamo nešto drugačiju sliku stanja i problema. Više od polovine ljudske populacije je već neko duže vreme u kućnom pritvoru. Naš životni prostor u kome smo provodili vreme uključujući i povremena turistička putovanja sveden je na naš stambeni prostor (Yeung \& Johnston, 2020). Naš stambeni prostor u kome smo prinuđeni da provodimo vreme je jedan novi izazov za wellness. Ovo novo okruženje treba sagledati iz svih šest navedenih perspektiva ili dimenzija opšteg zdravlja (fizičko, mentalno, socijalno, emocionalno, duhovno i okruženja) (Global Wellness Institute - GWI, 2020b).

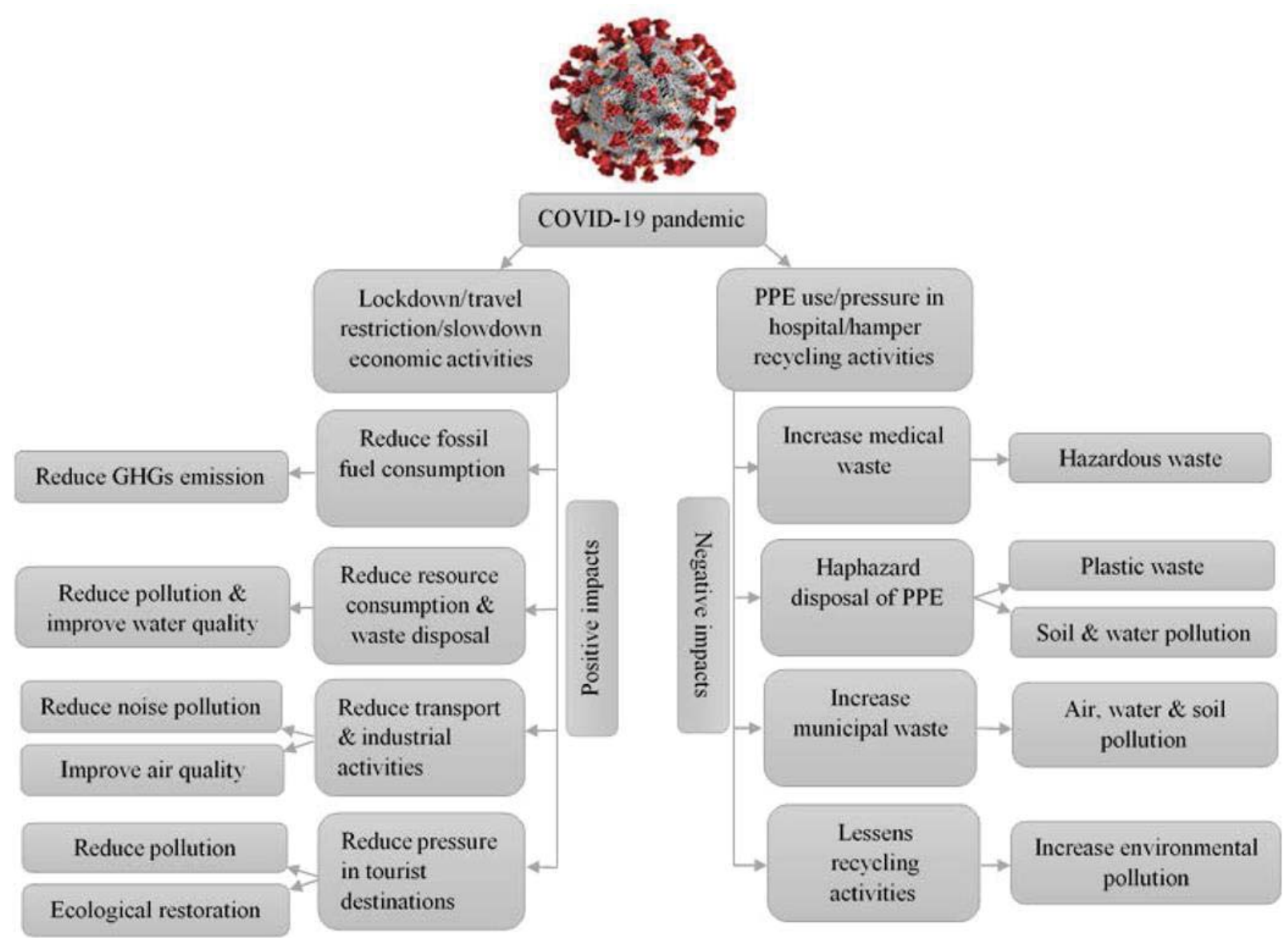

Slika 4. Pozitivni i negativni ekološki efekti pandemije COVID-19

Figure 4. Positive and negative environmental effects of pandemics COVID-19

Izvor / Source: (Rume \& Didar-UI Islam, 2020) 
Prema istraživanju (Global Wellness Institute GWI, 2020a) oko $15 \%$ svetske populacije i pre pandemije pati od nekog od oblika mentalnih bolesti. Pandemia COVID-a 19 je značajno negativno uticala na naše mentalno stanje i opšte mentalno zdravlje cele populacije. Stambeno okruženje i stresovi su uticali na rast raskoraka između zahteva, odnosno naših potreba za ostvarivanje opšteg zdravlja i mogućnosti da ih realizujemo. Prvi put je tada značajnije sagledan više aspektni uticaj okruženja na naše mentalno zdravlje. Definisan je pojam mentalnog wellnes-a (ili mentalno zdravstvena dobrobit). Navodi se u izveštaju, da je mentalni wellnes viđen kao resurs koji nam pomaže da razmišljamo, osećamo i funkcionišemo u svom okruženju. To je jedan aktivan proces koji nam pomaže da budemo elastični na okolnosti, da se dalje razvijamo i osećamo zadovoljni. On ima svoje četiri dimenzije, to su:

1. mentalna (kako obrađujemo i razumemo informacije),

2. emocionalna (kako razumemo i izražavamo svoje emocije),

3. socijalna (kako se povezujemo sa drugim ljudima),

4. psihološka (kako stvari sastavljamo i povezujemo zajedno da bismo doneli svoje odluke).

Prema istom izvoru (Global Wellness Institute GWI, 2020a), posledice izmenjenog okruženja i doživljenog stresa, zahtevaju posebnu pažnju, kako pojedinaca tako i kreatora politike u narednom periodu. Procenjuje se da će rast mentalnih bolesti u svetu dovesti do povećanja globalnih troškova lečenja mentalnih bolesti na 16.1 hiljada milijardi USA\$ do $2030 \mathrm{~g}$. Posledice će se osetiti na individualnom, porodičnom ali i društvenom nivou.

Korišćenje zelenih površina može smanjiti pritisak na naše mentalno, emocionalno, psihičko i fizičko stanje zdravlja (Kondo, Fluehr, McKeon, \& Branas, 2018). Pozitivni efekti koji se odnose na smanjenje zagađenja, buke, povećanje fizičke i kognitivne mogućnosti utiču na naše poboljšanje opšteg zdravlja i smanjenje agresivnosti i negativnih osećanja. Ovo je posebno bitno za ljude koji žive u velikim urbanim naseljima. Grupa utora u svom izveštaju (Barton \& Rogerson, 2017) navode da u svetu postoji potreba da se hitno reaguje za formiranje infrastrukture za mentalno zdravlje. $U$ radu se navodi da je mentalno zdravlje veliki uzrok raznih psiho somatskih oboljenja. Trošak lečenja pacijenata sa mentalnim bolestima se kreće oko 1,6 milijardi funti godišnje. Zelene površine ili zeleni prostor kako se još zovu ove namenske površine pokazuju veliku korelaciju između njihovog postojanja i mentalnog zdravlja i osećaja blagostanja u gradovima. Čak i pojedinci koji se presele iz manje u više zelene delove grada pokazuju poboljšanja mentalnog zdravlja. Fizička aktivnost koja se odvija u zelenim površinama nazvana je „zelena vežba“. Pri tome jezera i reke imaju podjednako značajan doprinos kao i zeleni prostor.

\section{ZAKLJUČAK / CONCLUSION}

Problem je u tome što je zdravstveni sistem reaktivan, jer reaguje tek nakon pojave znakova bolesti. Baveći se pri tome, ublažavanjem posledica bolesti a retko kada lečenjem uzroka. Wellness je sa druge strane proaktivan pristup koji se bavi preventivnim ulaganjem u dostizanje optimalnog opšteg zdravlja. Posmatra opšte zdravlje čoveka kao jednu celinu sastavljenu iz šest dimenzija (fizičko, mentalno, socijalno, emocionalno, duhovno i okruženje u kome živi). Osećaj opšteg zdravlja se postiže samo uravnoteženim pristupima svih dimenzija opšteg zdravlja. WelIness model zdravlja treba da ukaže svakom pojedincu na određene veze između njegovih potreba, ograničenja i okruženja. Ova analiza međusobnih veza treba da pomogne u sagledavanju mesta gde su relacije narušene i gde treba uložiti dodatne napore. Zato wellness pristup veliki deo uloge i odgovornosti prebacuje na pojedinca koji treba da se prvo edukuje a zatim da primenjuje naučeno u svojim svakodnevnim navikama. Da radi na svom povezivanju sa drugim ljudima, razvija svoje mogućnosti i interesovanja, primenjuje zdrav način ishrane i vežbanja ali i da radi na očuvanju prirode iz koje dobija svoje resurse.

lako zarazne bolesti predstavljaju samo jednu četvrtinu uzroka smrti u svetu, do pojave pandemije, naš ekološki sistem u gradovima igra enormno veliku ulogu u našim životima. Najnovija istraživanja pokazuju da 80 do $90 \%$ rizika za pojavu bolesti zavise od faktora iz našeg neposrednog okruženja. Onih preostalih oko $20 \%$ čine genetske predispozicije koje se mogu aktivirati u određenom nepovoljnom okruženju i mogu biti uzročnici hroničnih bolesti. Faktori okruženja su podeljeni u tri grupe: prirodno okruženje, zdravstveni (i ostali komunalni) sistemi i socioekonomsko okruženje. Faktori našeg neposrednog okruženja su naši domovi, komšiluk, poslovno i socijalno okruženje i objekti u kojem provodimo vreme. Naše okruženje čine i prirodno okruženja u kome ste proveli vreme, kao što su parkovi, obale reka i sl. Tu treba dodati hranu, vodu; zdravstveni sistem (i ostali komunalni sistemi), socio-ekonomsko okruženje koje smo sami kreirali. U zavisnosti od faktora okruženja može se u velikoj meri predvideti dužina života. Povoljnije okruženje stvara preduslove za duži i kvalitetniji život.

Kao posledica sprovođenja mera za zaustavljanje pandemije javili su se mnogi efekti po okruženje u gradovima i životnu sredinu. Ovo je omogućilo 
obnavljanje ekoloških sistema. Istraživanja pokazuju da je došlo do smanjenja zagađenja vazduha, vode, buke, emisije štetnih gasova i pritiska na turističke destinacije. Javili su se i mnogi negativni efekti po prirodnu sredinu kao što je porast medicinskog $i$ opasnog otpada, smanjenje recikliranja materijala, porast komunalnog otpada i sl.

Ovaj koncept provođenja života u ograničenom prostoru i pored savremenih oblika komunikacije je za većinu čovečanstva potpuno nov. Socijalna otuđenost u kombinaciji sa raznim stresovima usled bolesti, gubitka posla, ili bliskih osoba doprinela je sa svoje strane značajnom porastu mentalnih bolesti. Mentalno stanje nacije će biti jedan od značajnih problema javnog zdravlja nakon prestanka pandemije i obnavljanje života.

Zelene površine u gradovima često se tretiraju samo kao vizuelni elementi urbanog dizajna iako brojna istraživanja pokazuju velike koristi koje ljudi, koji stanuju u blizini, imaju od korišćenja ovih površina. Koristi se odnose na sve aspekte zdravlja ljudi. Nikada nije postojao bitniji faktor od zdravlja za izlazak iz krize i ekonomsku obnovu života. Upravo je primena wellness-a to rešenje ka kome se treba težiti, radi oporavka i očuvanja zdravlja ali i jedinstva čoveka sa prirodom.

\section{LITERATURA / REFERENCES}

[1] Barton, J., \& Rogerson, M. (2017). The importance of greenspace for mental health. BJPsych Int, str. 79-81.

[2] Beke-Trivunac, J., \& Jovanović, L. (2020). Municipality budget changes over the year as an indicator of environmental management policies. Ecologica, 27(97), 5-14.

[3] Bradley, W. (2020). Salem Press Enciclopedia of Health. Salem Press.

[4] Dubos, R., \& Mechanic, D. (1968). So Human an Animal: How We are Shaped by Surroundings. CharlesScribner's Sons.

[5] Global Wellness Institute - GWI. (2020a). Defining the Mental Wellness Economy. GWI.

[6] Global Wellness Institute - GWI. (2020b). 2020 COMPENDIUM - Resetting the World with Wellness. Preuzeto January 30, 2021 sa:

https://globalwellnessinstitute.org/wp-content/ uploads/2020/08/2020_White_Paper_Series_Re setting_the_world_with_Wellness_Revised.pdf

[7] Global Wellness Institute - GWI. (2021). Wellness definition. Preuzeto January 30, 2021 sa: https://globalwellnessinstitute.org/what-iswellness/
[8] Kondo, M., Fluehr, J., McKeon, T., \& Branas, C. (2018). Urban Green Space and Its Impact on Human Health. International Journal of Environmental Research and Public Health - IJERPH, $5(3)$.

[9] Lukinović, M., \& Jovanović, L. (2020). Uticaj pandemije COVID-19 na životnu sredinu. Ecologica, 27(99), 376-382.

[10] Munitlak-Ivanović, O. (2020). Razvoj pametnih gradova - primer četvrte industrijske revolucije. Ecologica, 27(97), 15-21.

[11] National Wellness Institute - NWI. (2021). The Six Dimensions of Wellness. Preuzeto January 29, 2021 sa National Wellness Institute - NWI: https://nationalwellness.org/resources/sixdimensions-of-wellness/

[12] Prüss-Ustün, A., Wolf, J., Corvalán, C., Bos, R., \& Neira, M. (2016). Preventing disease through healthy environments: a global assessment of the burden of disease from environmental risks. Revue d'Epidemiologie et de Santé Publique, DOI 10.1016/j.respe.2016.09.001.

[13] Rappaport, S., \& Smith, M. (2010). Environmental and Dlsease Risk. Science, 330(6003), pp 460461 DOI: 10.1126/science. 1192603.

[14] Rume, T., \& Didar-UI Islam, S. (2020). Environmental effects of COVID-19 pandemic and potential strategies. Heliyon, 6(9), E04965, DOI: https://doi.org/10.1016/j.heliyon.2020.e04965.

[15] World Healt Organisation - WHO, Climate \& Clean Air Coalition-CCAC. (2021). Breath Life The Equatation is Simple. Preuzeto sa World Healt Organisation: www.who.int > breathelifeequation-is-simple-flyer

[16] World Health Organisation - WHO. (2020). The top 10 causes of death. Preuzeto February 1 , 2021 sa Healt Topics: https://www.who.int/newsroom/fact-sheets/detail/the-top-10-causes-ofdeath

[17] World Health Organization - WHO. (2018). Key facts. Preuzeto sa Household air pollution and health: https://www.who.int/news-room/factsheets/detail/household-air-pollution-andhealth\#: :text=Household\%20air\%20pollution\% 20 causes $\% 20$ noncommunicable,inhaled $\% 20$ fro $\mathrm{m} \% 20$ household\%20air\%20pollution.

[18] Yeung, O., \& Johnston, K. (2020). Resetting the World With Wellness: A New Vision for a Post Covid 19 Future. Global Wellness Institute GWO. 